\title{
The Effect of Weight Loss on Some Physical Fitness Factors of Wrestlers
}

\author{
Izzet Uçan \\ Correspondence: Izzet Uçan, School of Physical Education and Sport Sciences, Bayburt University, Turkey.
}

Received: July 10, $2018 \quad$ Accepted: July 25, $2018 \quad$ Online Published: August 1, 2018

doi:10.11114/jets.v6i9a.3508

URL: https://doi.org/10.11114/jets.v6i9a.3508

\begin{abstract}
The main purpose of this research was to investigate the effect of weight loss on some physical fitness factors of wrestlers. So thirty wrestlers were voluntarily selected and randomly divided into two groups $(n=15)$; active and sauna groups. They participated in some motor fitness factors tests such as; Sargent tests to measure the anaerobic acidalkaline power, chest press for strength measurements, dynamic balance and coordination. We found that acute dehydration in the active group had a significant effect on strength, balance and coordination, but did not have a significant effect on strength. In sauna group, the effects of acute dehydration on strength and balance were significant but did not have a significant effect on strength.
\end{abstract}

Keywords: fast weight loss, dehydration, physical and muscular fitness

\section{Introduction}

Athletes need to have physical fitness and proper body composition, especially ideal weight, for their achievement. Among the sports fields, wrestling is one of the most famous sports in terms of relationship with weight control and energy management methods. Dehydration is the fastest way to lose weight (Almond et al, 2005). Most wrestlers use sunshades and diuretics for weight loss (with weight gain), along with severe dietary restrictions, and especially liquids, such as jogging with plastic suits for sweating.

Using such diets, along with physical exercises and excessive sweating, will cause dehydration and electrolyte imbalance. On average, before the competition, between $2 \%-3 \%$ of the weight is reduced by athletes, and the most part of this weight loss is done in the final days or the day before weaning. The wrestlers may participate in 15 to 30 matches throughout the year, so it's unusual to repeat the weight loss over a season (Convertino et al, 2010). If $1 \%$ of the weight of the athlete is reduced due to dehydration, osmotic receptors in the body are stimulated and thirst is achieved in the body. If the amount of water deficit reaches $3 \%$, the athlete's ability decreases and negatively affects the quality of his sports activities. Therefore, it is imperative that athletes have enough information about this and drink enough water before they are thirsty (Aldridge et al., 2017). The body's dehydration rate reaches $4 \%$ of body weight, with $30 \%$ of its abilities and the quality of exercise decreased. Therefore, sports physicians always repeat this statement (drink water before thirst and get it out of the urine as drink excess water). Athletes know that due to body heat loss and sweating during exercise, water is reduced, so the best way to do this is to drink water while exercising (Aldridge et al., 2017).

The exact way to get rid of water intake in the body is to drink 1 milliliter per 1 kilocalory of energy consumption. The simplest and most practical way to control athletic weigh loss is before and after exercise, and usually the body weight loss is the same as the body weight loss. Usually, for every 1 hour of physical activity, 2 liters of sweating are performed, and the same amount of water is reduced (Aldridge et al., 2017).

Rapid weight loss increases the body's response time due to changes in plasma volume, changes in ionic concentration, and concentration of electrolytes in the nervous and muscular cells and decreases strength, speed and muscle endurance (Benrdot, 1995). Because high-intensity activities have low metabolic requirements, it has a modest effect on the body. Therefore, many researchers assume that hypo- hydration directly affects the nervous system and then affects the relationship between the nervous system and the muscular system.

There are several ways to dispose of waste material from the body. Man has limitations on the production of stool, urine, sweat and respiration. When the liver, kidneys and lungs are placed in the vicinity of peripheral waste, they are severely damaged and their ability to exhaust these waste materials is limited. There are several ways to clean the liver and kidneys from the waste. Today, studies show that between 400 and 800 different chemicals are stored in fat cells. 
The amount of sweating that takes place every 30 minutes in the sauna is equivalent to sweat that runs 10 kilometers away, our body sweats to cool (American College of Sports Medicine, 2010). Daniel et al. (2008) found that hypochondriasis increased cortisol and norepinephrine hormones and reduced the effect of testosterone and altered carbohydrate and lipid metabolism. They examined the effects of hydration on exercise performance and found that a $2 \%$ reduction in body water levels in endurance athletes would be affected by hard aerobic activity (Daniel et al., 2008). Almond et al. (2005) examined a variety of hydration conditions on professional rugby players in a study, observing that athletes who underwent continuous activity for 30 minutes and did not exercise hydration, $\mathrm{Vo}_{2 \max }$ and heart rate and Urine concentrations and RPE showed a significant increase compared to the hydration group (Almond et al. 2005).

Jeffrey (2011) examined the effects of dehydration and routine on male chest press and found that inactive passive dehydration reduced the rate of chest press by $5.6 \%$ and was compensated after 2 hours of rest and recursion, they also examined the effects of active dehydration, and found that by reducing the $4.9 \%$ of body weight to iso-synthetic torque and work of wrestlers negatively (Jeffrey, 2011). Rena and Coles (2012) examined the effects of hypo hydration on strength training and found that hypo hydration does not affect strength (Pelliccia et al., 2009).

Opik et al. (2010) investigated the effects of rapid weight loss on metabolic capacity and isocratic contraction on two wrestlers. It was found that a decrease in the body weight of $1.5-5.5 \%$ reduced the volume of blood the size of 7-14-4.8\%, and the isokinetic and metabolic functions of the quadriceps were low (Opik et al., 2010). According to the results of the research, repetition of rapid weight loss and dehydration for several times during the year to reach a lower weight class could have a negative effect on the performance of the shipyard. Therefore, it seems that in a country like Iran, which is the first-nation and national sports boat, in order to inform more educators and athletes who have little information about the consequences of a rapid weight loss and at the same time recommend it and conduct it, conduct research comprehensive in this area is essential.

In a study conducted by Carter et al. (2006), they examined the effects of hypochondria in cold environments. Body fluid needs should be similar to neutral environments due to increased metabolic costs in the winter, preventing the body from cooling it through the body. The direct effects of cold on hydration conditions include limitation of thirst and urinary excretion due to cold stimulation, both responses reduce total body water when exposed to cold. Soldiers who work in cold weather lose 2.5 percent of their body weight due to dehydration. In warm environments, hypo-hydration may reduce exercise and normal body function and increase the risk of heat loss. Hypo-hydration increases the risk of hyperthermia and cold-related injuries (Carter et al., 2006).

In a study conducted by Pelliccia et al., (2009), they found that hypo hydration had no effect on power. In another study conducted by Ismail et al. (2017), they found that passive dehydration reduced the $5.6 \%$ reduction in the chest press record and, after 2 hours of rest and recursion, was compensated for this decrease, as well as the effects of active dehydration and found that with a reduction of $4.9 \%$ of body weight negatively impact on the ISO and wrestling performance (Ismail et al., 2017). In a study conducted by Steven (2003), he examined the effects of rapid weight loss on boxers' performance. All subjects lost their body mass and the average dehydration rate were $3.8 \%$, but plasma changes were contradictory. The plasma levels decrease from $15 \%$ to $30 \%$. Body strength and body size decreased in subjects and their performance dropped to $26.8 \%$ (Steven, 2003). Opik et al. (2010) found that reducing the body weight of $5.16 \%$ to $1.5-5 \%$ reduced the blood volume by as much as $14.4-4.7 \%$ the isokinetic and metabolic functions of the quadriceps were low (Opik et al., 2010). The American College of Sports Medicine (2017) stated that until the researchers have researched their effects on the effects of hypo hydration on strength and strength exercises, body hydration is recommended to be maintained at normal levels (American College of Sports Medicine, 2017). In a study conducted by Moghaddami (2015), he found that the rapid dehydration has some negative effects of rapid dehydration on motor fitness such as sprint, reaction time and agility. Considering that the readiness indicators for wrestlers play a decisive role in their performance, it is possible to negatively affect readiness of the wrestlers. Therefore, the present study intends to compare the effect of two types of weight loss through acute dehydration on motor readiness. Now the research has decided to study the effect of sauna on some motor fitness of wrestlers.

\section{Methods}

The method of this research was a semi-experimental design. In this research, the weight loss rate of the wrestlers was $3.5-4.3 \%$ of the body weight. The method of implementation, necessary points and necessary recommendations were explained and also dehydration status was standardized through the same diet and fluids. On the day of the pre-test, the subjects ate a standard break rapid and $500 \mathrm{ml}$ of water and participated in the necessary tests after an hour.

\subsection{Statistical Society}

The statistical population of this research consisted of 20 wrestlers in Erzurum which were randomly divided into two groups $(\mathrm{n}=15)$. 


\subsection{Statistical Sample and Sampling Methods}

The subjects of this study were wrestlers between 17 to 23 years old. Sampling was done from available subjects. In this way, after informing and inviting interested persons and completing the registration process, 20 questionnaires were filled out and they were divided randomly into two groups; active and sauna.

\subsection{Research tool}

1. Health Questionnaire.

2. 160 kilograms KAMOSHITA scale with a precision of 100 grams made in Japan.

3. Smith machine for chest press made by China.

4. Sargent device for measuring muscular strength of quadriceps made by China.

\subsection{Research Methodology}

After collecting the data in the pre-test, the subjects were randomly divided into two groups, active and sauna. The next day at 4:00 PM, group two sat in the sauna and 3 times in 20 minutes in sauna and 5 minutes off between every 20 minutes and in this way they lowered their weight. The weight of the subjects was recorded at any time of rest. After lowering 4.5-4.3\% of their body weight and getting the required weight, the subjects participated in the posttest 1 and next day participated in the post- test 2. In group 1, we used the Singh and Sirisingheh method (2017) to lower the weight. The subjects started running on a treadmill with $65 \% \mathrm{VO}_{2} \max$ for 90 minutes. The maximum oxygen consumed by athletes was calculated by Balk test.

After lowering 3-4\% of their body weight, they participated in the posttest 1 and participated in the post-test 2 simultaneously with the sauna group. The time interval between lowering the body weight and performing the second test is according to the rules of the wrestling (Klavora, 2008).

Tests performed by the two groups in them and in three stages of pretest and posttest 1 and post-test 2 included:

1. Sargent test for quadruple muscle strength.

2. Chest press test to measure breast muscle strength.

3. Hexagonal Test for Balancing and Coordination

\section{Results}

Table 1. Physical characteristics and motor fitness variables

\begin{tabular}{ccccccc}
\hline Variables & Age $(\mathrm{yrs})$ & $\begin{array}{c}\text { Weight } \\
(\mathrm{Kg})\end{array}$ & $\begin{array}{c}\text { Height } \\
(\mathrm{cm})\end{array}$ & $\begin{array}{c}\text { Power } \\
(\text { Watts/Kg) }\end{array}$ & $\begin{array}{c}\text { Balance } \\
(\mathrm{S})\end{array}$ & Chest press $(\mathrm{Kg})$ \\
\hline Mean & 19.68 & 68.53 & 173.843 & 941.11 & 12.91 & 64.167 \\
\hline St. dev. & 1.97 & 8.53 & 7.152 & 242.71 & 0.79 & 13.80 \\
\hline
\end{tabular}

Table 2. Mean and standard deviation of measured variables in the pre-test

\begin{tabular}{lcccc}
\hline \multirow{2}{*}{ Variable } & \multicolumn{2}{c}{ Active group } & \multicolumn{2}{c}{ Sauna group } \\
\cline { 2 - 5 } & $\mathrm{M}$ & Std. dev. & $\mathrm{M}$ & Std. dev. \\
\hline Power $(\mathrm{W} / \mathrm{Kg})$ & 1007.732 & 143.7355 & 874.4884 & 306.3398 \\
\hline Balance $(\mathrm{S})$ & 12.691 & 0.5595 & 13.139 & 0.9456 \\
\hline Strength $(\mathrm{Kg})$ & 66.333 & 12.3006 & 62 & 15.4927 \\
\hline
\end{tabular}

Table 3. Mean and standard deviation of measured variables in post-test 1

\begin{tabular}{lcccc}
\hline \multirow{2}{*}{ Variable } & \multicolumn{2}{c}{ Active group } & \multicolumn{2}{c}{ Sauna group } \\
\cline { 2 - 5 } & $\mathrm{M}$ & Std. dev. & $\mathrm{M}$ & Std. dev. \\
\hline Power $(\mathrm{W} / \mathrm{Kg})$ & 951.8125 & 135.4606 & 1737.169 & 266.2659 \\
\hline Balance $(\mathrm{S})$ & 13.5026 & 0.7379 & 13.5493 & 0.6766 \\
\hline Agility $(\mathrm{s})$ & 9.6943 & 1.045 & 9.621 & 1.1035 \\
\hline Strength $(\mathrm{Kg})$ & 65.600 & 13.2337 & 61.766 & 15.8986 \\
\hline
\end{tabular}


Table 4. Mean and standard deviation of measured variables in post test 2

\begin{tabular}{lcccc}
\hline \multirow{2}{*}{ Variable } & \multicolumn{2}{c}{ Active group } & \multicolumn{2}{c}{ Sauna group } \\
\cline { 2 - 5 } & $\mathrm{M}$ & Std. dev. & $\mathrm{M}$ & Std. dev. \\
\hline Power $(\mathrm{W} / \mathrm{Kg})$ & 967.8966 & 140.8298 & 898.888 & 139.5268 \\
\hline Balance $(\mathrm{S})$ & 13.5463 & 0.6151 & 14.094 & 2.0274 \\
\hline Strength $(\mathrm{Kg})$ & 65.7332 & 12.4679 & 61.833 & 12.4679 \\
\hline
\end{tabular}

Table 5. Effect of dehydration on variables in active group

\begin{tabular}{lllll}
\hline \multirow{2}{*}{ Test } & \multicolumn{1}{c}{ Variable } & \multicolumn{1}{c}{ M } & M Er & Sig. \\
\hline \multirow{2}{*}{ Sargent } & Pre-test & 1007.7317 & 1.710 & $0.000^{*}$ \\
\cline { 2 - 5 } & Post- test 1 & 951.8125 & -1.710 & $0.000^{*}$ \\
\cline { 2 - 5 } & Post-test 2 & 967.8960 & -0.835 & $0.068^{*}$ \\
\hline \multirow{2}{*}{ Balance } & Pre-test & 12.6913 & -0.811 & $0.02^{*}$ \\
\cline { 2 - 5 } & Post- test 1 & 13.5026 & 0.811 & $0.02^{*}$ \\
\cline { 2 - 5 } & Post-test 2 & 13.5463 & 0.855 & $0.02^{*}$ \\
\hline Chest press & Pre-test & 66.333 & 0.733 & 0.721 \\
\cline { 2 - 5 } & Post- test 1 & 65.666 & -0.733 & 0.721 \\
\cline { 2 - 5 } & Post-test 2 & 65.733 & -7.967 & 0.919 \\
\hline
\end{tabular}

As the result of table 5 shows, the Sargent test, balance results are significantly different in Pre, post 1 and post 2 tests. The results shows chest press results are not significantly different in Pre, post 1 and post 2 tests.

Table 6. Effect of dehydration on variables in sauna group

\begin{tabular}{llccc}
\hline \multicolumn{1}{c}{ Test } & \multicolumn{1}{c}{ Variable } & M & M Er & Sig. \\
\hline \multirow{2}{*}{ Sargent } & Pre-test & 874.4884 & -862.681 & 1.000 \\
\cline { 2 - 5 } & Post- test 1 & 1737.169 & 862.681 & 1.000 \\
\cline { 2 - 5 } & Post-test 2 & 874.1848 & -49.304 & $0.000^{*}$ \\
\hline \multirow{2}{*}{ Balance } & Pre-test & 12.1391 & -0.410 & 0.048 \\
\cline { 2 - 5 } & Post- test 1 & 13.5493 & 0.410 & 0.048 \\
\cline { 2 - 5 } & Post-test 2 & 14.0943 & 0.955 & 0.009 \\
\hline Chest press & Pre-test & 62 & 0.233 & 1.000 \\
\cline { 2 - 5 } & Post- test 1 & 61.7666 & -0.233 & 1.000 \\
\cline { 2 - 5 } & Post-test 2 & 61.8333 & -0.167 & 1.000 \\
\hline
\end{tabular}

As the result of table 6 shows, balance results are significantly different in Pre, post 1 and post 2 tests among subjects. The results shows Sargent test and chest press results are not significantly different in Pre, post 1 and post 2 tests among subjects.

\section{Discussion and Conclusion}

Due to the rapid reduction of body weight in different sports, various injuries are brought to the athlete's performance. Some physical-motor fitness variables were investigated in this study. In the active group, acute dehydration had a significant effect on wrestlers' ability in both post-test 1 and post-test 2 , but in the sauna group in post-test 1 , this change was not significant. In post- test 2 , this change was significant. This research finding is consistent with the results of other researches.

Robert et al. (2010) showed that rapid reduction of body weight through sauna and medication and wearing plastic clothes could reduce the anaerobic power of wrestlers (Robert et al., 2010). Jodelson et al. 2017 showed that different conditions of hydration in the body have different effects comes up. This effect was not significant at jump height, but it had a significant effect on Scott's jump (Convertino et al., 2010). Daniel et al. (2008) showed that rapid dehydration could affect the strength and power of athletes (Daniel et al., 2008). Researchers have argued that because of the power movement is closely related to the nervous system, the first pressure on dehydration is introduced into the nervous system and one of the causes of exercise loss is announced and also, some studies suggest another cause of dehydration due to the disruption of metabolic pathways and disturbances in body heat rejection. Some researchers say that because high-intensity activities have low metabolic requirements, it results in a slight warming effect on the body.

Therefore, many researchers assume that hypo-hydration directly affects the nervous system and then affects the 
relationship between the nervous system and the muscular system. Any disturbances in conduction of neural impedances disrupt the transfer of neural impulses from the nervous system to the muscles or muscle responses to the nervous system, which has obvious effects on exercise performance (both endurance activities and resistance activities). Because any decrease in cell water affects its function (Robbert et al., 2011).

Gutiérrez et al. (2003) found that the sauna causes dehydration and causes rapid weight loss in men and in women. This reduction is not quickly compensated through raids. The weight loss program does not affect the strength and ability of male mutations. But in women, there is a significant drop in the ability to scoop up, which was compared with that of rehydration. Scott jumps dropped linearly in women, indicating that they were associated with a percentage of body weight loss.

Another finding of this study was that dehydration had a significant effect on the balance of the active group and the sauna group. Acute dehydration in the active group and in the post-test 1 caused a decrease in the balance of the wrestlers and also in post- test 2 , this decline continued.

In the sauna group, the rapid dehydration of the body also caused a loss in the balance of the wrestlers, and this decline continued in the post- test 2 . Unfortunately, little research is available on the effect of water deficit on equilibrium. This result is in line with the results of some researches and does not work with others.

Takeshi et al. (2017) found that dehydration caused a loss of energy balance in the body, and the balance of the hormonal system collapsed, all of which caused a loss in static equilibrium on one leg, and generally declared that the function Nervous muscles and firmness are affected by dehydration (Takeshi et al., 2017). The American Medical and Athletic Committee has stated that rapid weight loss causes a dramatic drop in anesthetized wrestlers' capacity and also damages the dynamic balance of athletes, but does not have a significant impact on the static balance of the wrestlers. Maughan (2012) found that neuromuscular coordination in female athletes was reduced. It seems that the reduction of muscle neuromuscular coordination plays a direct role in maintaining equilibrium of athletes, and the drop in it will reduce the balance of athletes (Rehrer et al., 2007).

Jeffrey et al. (2011) found that dehydration in the body causes hypoglycemia in the blood and it also causes carbohydrates to be consumed in the body quickly and imperfectly, leading to insulin accumulation in the blood and loss of blood glucose, and, on the other hand, lowering the carbohydrate intake in the body also results in a decrease in muscle function (Jeffrey, 2011).

Another result in this study was that there was no significant effect on the strength of the wrestlers in the saunas and in the active group of acute dehydration in post-test 1 and post-test 2 . This result is consistent with some of the other research results and is not consistent with some others. Daniel et al. (2008) found that hypochondria most affect their athletic aerobic performance, resulting in a 15 percent drop in their weight and have no effect on the athlete's power. Bijlani (2011) also found that dehydration in the body had no significant effect on the strength of athletes (Bijlani, 2011).

Ismail et al. (2017) found that passive dehydration reduced the 6.6\% reduction in the chest press record and, after 2 hours of rest and recursion, was compensated for this decrease, also examined the effects of active dehydration, and found this which resulted in a $4.9 \%$ reduction in body weight on isocratic strength and wrestling performance. They reported hypoglycemia, which occurred as a result of the increased secretion of insulin hormone that occurred during post-dehydration activity, due to a decline in athletes' record (Ismail et al., 2017).

Dehydration (through the sauna and diet and medication) did not affect the isometric power of the knee extensor muscles. The protocols used in this study (hot air activity) indicated that reducing inactive water (sauna and medication) had no effect on muscle tiredness. Subjects of this study after the dehydration did not show any reduction in the strength of the maximal knee extensor. When rapid dehydration occurs, heat dissipation is problematic, resulting in an increase in deep temperature and increased blood levels that are dangerous to the health of athletes (Kovacs et al., 2012).

The results indicate that dehydration reduces muscle flow during exercise and reduces the transport of glucose in the blood, resulting in accumulation of lactate in prolonged exercise and early fatigue. But Szinnai et al. (2005) found that the reduction in blood flow that occurs in the body due to dehydration does not affect the transfer of glucose and free fats and the elimination of lactic acid during long-term, medium-intensity activity. But during dehydration, dehydration oxidizes carbohydrates and increases lactic acid production (Szinnai et al., 2005). Burke et al (2000) found athletes in the warm air dropped by $3 \%$ of body weight from dehydration in warm air athletes. In this study, the cause of this decline was the depletion of intracellular fluid and local muscle tiredness (Burke et al., 2000). Comparing the results of this study shows that weight loss in both active and sauna use has similar effects on the readiness of the wrestlers. 


\section{References}

Aldridge, G., Baker, J. S., \& Davies, B. (2017). Effects of Hydration Status on Aerobic Performance for a Group of Male University Rugby Players, Journal of Exercise Physiology Online, 8(5), 110-118.

Almond, Y., \& Shin, B. (2015). Hyponatremia among runners in the Boston marathon, 352, 1550-1556.

American College of Sports Medicine. (2010). Position statement exercise and fluid replacement, Med Sci Sports Exer, 28, i-vii.

Benrdot, D. (2010). Nutrition for Serious Athletes. Human Kinetics, 244-247.

Bijlani, S. (2011). Effect of Dehydration and a Few Regimes of Rehydration on Human Performance. Indian J Physiol. Pharmacol., 24, 255-266.

Burke, L., \& Deakin, V. (2010). Clinical Sport Nutrition Second Edition, Mcg Raw Hill Companies, Inc.146-163 .

Convertino, V., Armstrong, L., Coyle, E., \& Mack, G. (2010). American College of Sports Medicine. Position Stand on Exercise and Fluid Replacement. Med. Sci. Sports Exerc., 28, 1-7.

Gutiérrez, J. L. M., Mesa, J. R., Ruiz, L. J., \& Chirosa, M. J. (2003). Sauna-Induced Rapid Weight Loss Decreases Explosive Power In Women but Not In Men., 518-522.

Ismail, R., Singh, R., \& Sirisinghe, G. (2017). Rehydration with Sodium-Enriched Coconut Water after Exercise-Induced Dehydration. Southeast Asian J. Trop Med Public Health, 769-785.

Judelson, D. A., Maresh, C. M., Yamamoto, L. M., Farrell, M. J., Armstrong, L. E., Kraemer, W. J., ... \& Anderson, J. M. (2008). Effect of hydration state on resistance exercise-induced endocrine markers of anabolism, catabolism, and metabolism. Journal of Applied Physiology, 105(3), 816-824. https://doi.org/10.1152/japplphysiol.01010.2007

Klavora, P. (2008). Foundation of Physical Activity, Canada, Sport Books Publisher, Second Edition.

Kovacs, M. R., Schmahl, R. M., Senden, J. M. G., \& Brouns, F. (2012). Effect of high and low rates of fluid intakes on post-exercise rehydration. Int. J. Sport Nutr. Exerc. Metab., 12, 14-23. https://doi.org/10.1123/ijsnem.12.1.14

Maughan, R. (2012). The Athlete's Diet: Nutritional Goals and Dietary Strategies. Proceedings of the Nutrition Society, 61(10), 87-96.

Moghaddami, A. (2015). Effect of two weight loss methods of acute dehydration on some physical-motor fitness factors of wrestlers, MA thesis, Tehran University.

Noakes, T. D., Rehrer, N. J., \& Maughan, R. J. (1991). The importance of volume in regulating gastric emptying, Med. Sci. Sports Exerc., 23(3), 307-313. https://doi.org/10.1249/00005768-199103000-00008

Oöpik, V., Pääsuke, M., Sikku, T., Timpmann, S., Medijainen, L., Ereline, J., ... \& Gapejeva, E. (1996). Effect of rapid weight loss on metabolism and isokinetic performance capacity. A case study of two well trained wrestlers. The Journal of Sports Medicine and Physical Fitness, 36(2), 127-131.

Pelliccia, A., Spataro, A., Caselli, G., \& Maron, B. J. (2009).Absence of Left Ventricular Wall Thickening in Athletes Engaged In Intense Power Training. Am. J. Cardiol., $72(14), \quad 1048-54$. https://doi.org/10.1016/0002-9149(93)90861-6

Rd, C. R., Cheuvront, S. N., Vernieuw, C. R., \& Sawka, M.N. (2006). Hypohydration and prior heat-stress exacerbates decreases in cerebral blood flow velocity during standing. Journal of Applied Physiology. https://doi.org/10.1152/japplphysiol.00200.2006

Rehrer, N. J., Brouns, F., Beckers, E. J., \& Saris, W. H. M. (2007). The Influence of Beverage Composition and Gastrointestinal Function On Fluid And Nutrient Availability During Exercise. Scandinavian Journal of Medicine \& Science in Sports, 4(3), 159-165. https://doi.org/10.1111/j.1600-0838.1994.tb00421.x

Robbert, A., Samuel, C., Craige, A., Gregory, L., \& Landy, A. (2011). Weight Loss in Wrestlers, American College of Sport Medicine, 27, 1220-1226.

Shemo, J. L. (2011). Practical Information for Sports Nutrition.

Steven, F. S. (2003). Quantifying Exercise Induced Dehydration, And Published In Rto-Mp-Hfm-086.

Szinnai, G., Schachinger, H., Arnaud, M. J., Linder, L., \& Keller, U. (2015). Effect of Water Deprivation On Cognitive-Motor Performance In Healthy Men And Women, Physiol Regul Inter Comp Physiol, 289, $275-280$. https://doi.org/10.1152/ajpregu.00501.2004 
Takeshi, N., \& Hirikazo, K. (2017). Alleviation of Exercise-Induced Dehydration under Hot Condition by Glycerol Hyper-hydration, International Journal of Sport and Health Science, 5, 32-41.

\section{Copyrights}

Copyright for this article is retained by the author(s), with first publication rights granted to the journal.

This is an open-access article distributed under the terms and conditions of the Creative Commons Attribution license which permits unrestricted use, distribution, and reproduction in any medium, provided the original work is properly cited. 